\title{
The Influence of Population Aging on the Urban Residents' Consumption and Economic Growth in Beijing-— the Empirical Study Based on VAR Model
}

\author{
Li Huishang, a , Cao Zhen ${ }^{2, \text { b }}$, Qu Chunhong ${ }^{1, ~ c, ~ *, ~ C u i ~ Y a j u a n ~}{ }^{3, \text { d }}$, Wang Meiling, \\ ${ }^{1}$ Agricultural Information Institute, Chinese Academy of Agricultural Sciences/Key Laboratory of \\ Agricultural Information Service Technology of Ministry of Agriculture, Beijing 100081, China; ${ }^{2}$ Guangxi \\ University, Nanning 530004, China; ${ }^{3}$ Beijing Institute of Nutritional Resources, Beijing 100069, China \\ alihsh2002@163.com, b18593995052@163.com, 'quchunhong@caas.cn, \\ d cuiyj66@163.com, ${ }^{\mathrm{e}} 1547241810 @ q q . c o m$ \\ *Corresponding author
}

Keywords: Aging of population, household consumption, economic growth, correlation analysis

\begin{abstract}
Taking Beijing city as an example, the relationship between aging of population, the consumption and the GDP in large city were studied based on the VAR model in the article. The results showed that there are closely relationship between the ratio of elderly dependency and consumption and economic growth. The population aging has a positive impact on household consumption increased with aging slightly, but there was a weak negative effect on economic growth. In view of the influence of population aging, the suggestions such as improving the social security system, developing new pension industry and promoting the optimization and upgrading of the dietary structure were put forward to realize the population, economic and social aspects developing synergistically.
\end{abstract}

\section{Introduction}

With the development of society and economy in China, especially the rising of the urbanization and health care level, the people's life expectancy was extended and the elderly population increased, so the population ageing problem has become one of the important problems. In recent years, the age structure in China has been significantly changed and the proportion of the elderly obviously increased. According to the statistics, the older population proportion above 65 years was about $14.33 \%$ in 2015. At the same time, China's economy has maintained a high level of economic development, but the residents' consumption rate has fluctuated which was 38.1\% in 2015 down 9.9 percentage points from 1999. At present, our country has entered the "new normal" of economic development and population pattern, and the influence of population on consumption affects the long-term development of the whole economy ${ }^{[1]}$. So the problems such as "not advanced but old" and "the disappearance of demographic dividend" had been gradually drop the attention of social and scholars.

As early as the middle of the 20th century, the theory of life cycle hypothesis had pointed out that consumption would be in accordance with the principle of the optimal configuration according to the utility maximization on the expected income in different age stages, which showed that the total consumption of society would decrease in the gradual process of population aging, but the consumption would increase after entering the aging society. Clark ${ }^{[2]}$ established an aging population economics, Modigliani ${ }^{[3]}$ analyzed the relationship between China's population dependency ratio and savings rate based on the life cycle theory, and believed that there were stable correlation. Horioka ${ }^{[4]}$ analyzed the consumption behavior of Chinese residents with GMM method, and found there was no significant correlation between population dependency ratio and saving rate. In these years, more and more domestic scholars has paid attention to the relationship between population aging and population consumption and economic growth. Studies had shown that the changes in age structure could significantly affect household consumption ${ }^{[5]}$ and the aging 
would increase household consumption level and promote consumption ${ }^{[6-7]}$. Li Chunqi ${ }^{[8]}$ pointed out that the ratio of the elder population dependency was negatively correlated with the consumption of rural residents. Wang Yupeng ${ }^{[9]}$ thought that the consuming behavior of Chinese urban residents would be significantly affected by the ageing population, the higher the aging population bring-up ratio and the higher the average propensity of urban residents to consume with other factors controlled. Shan $\mathrm{Yi}^{[10]}$ believed that the size increase of the elderly population and their consuming tendency would have impacts on the consumption of the residents and further affect the economic and social development. But Wang Jiaxu ${ }^{[11]}$ pointed out that the aging of population had significant negative effects on the gap between urban and rural residents' consumption and some scholars also thought there were positive-negative cross effects ${ }^{[12]}$. Some ${ }^{[13-16]}$ believed that population aging had a restraining effect on economic growth which was detrimental to the sustained and stable growth of China's economy in the long run. But also some scholars thought the effect was weak ${ }^{[17]}$ or the aging population was a negative factor of economic growth $^{[18]}$, while others thought that the ageing population had various effects on economic growth $^{[19-20]}$. Some researches ${ }^{[21]}$ also indicated that the aging population had a higher correlation with health care, education cultural entertainment and residential consumption in Beijing.

Current literatures showed that the results about population aging, household consumption and economic growth were not consistent and there were some differences in different regions. As the center of national politics, economy, science and technology and culture, Beijing was a typical megacity with more than 21 million residents. At the same time, the aging population also developed rapidly and had a certain impact on the consumption of residents and economic growth. The proportion of the aged 60 years and above in Beijing was 9.83\% and the proportion of elderly dependents was $8.89 \%$ in 1984 . The old-age dependency ratio reached a record $15.09 \%$ in 2008 and after that which fell back slowly. By the end of 2015, the aged was about 3.15 million and $23.4 \%$ of the total population, the net increase was more than 500 people above sixty years per day on average and more than 120 people net gain aged 80 or above and the elderly dependency ratio was $12.89 \%$, which was the $2^{\text {nd }}$ rank all over the country. Some reports forecast that the aging population of Beijing would be more than $30 \%$ in future and a further aging society. Therefore, taking Beijing for example to analysis the degree of relevance and interaction between the ageing population and the residents' consumption, economic and social development, putting forward relevant countermeasures would be necessary, which would be given some realistic references to other cities' construction and management and population policy and other policies.

\section{Model setting and variable selection}

The Vector Autoregressive Model was used in the article. Assuming that the population age structure as endogenous variables, the long-term equilibrium and short-term relationship between the population aging and residents' consumption level and regional economic growth in Beijing were qualitatively and quantitatively analyzed using stationarity test, Granger causality test and variance decomposition methods. The flowing is VAR model.

$$
Y_{t}=C+\sum_{i=1}^{n} \alpha_{t} Y_{t-1}+\varepsilon_{i}
$$

Among the model, $Y_{t}=\left[\begin{array}{l}e d r_{t} \\ c o n s_{t} \\ g d p_{t}\end{array}\right], \quad \mathrm{C}$ is the constant item sequence vector, $\mathrm{n}$ is the lagged order, $\varepsilon_{i}$ is the white noise sequence vector.

$e d r$ was the ageing population index. According to the internationally accepted indicators, the index was calculated using the proportion of the 65 years and older population accounts for 15 to 64-year-old labour (the population of permanent residents), which was the elderly dependency ratio as population aging evaluation index. cons was the residents' consumption level index. The consumption rate of residents could directly reflect the consumption ability and consumption level. 
The consumption rate was calculated with the consumption expenditure of urban residents in Beijing and the area gross domestic product (GDP) by the expenditure law to reflect the consumption level of urban residents in the article. For economic growth indicators, gdp was got rid of the inflation and price factors taking 1992 as the baseline. The data used in this paper are compiled and calculated according to the years of the Beijing statistical yearbook and the China statistical yearbook, and the time span is 1993-2015.

\section{Results}

\subsection{Stability test}

To eliminate sequence heteroscedasticity and variables with order single whole, the data were respectively token logarithm and made one order difference. The stability of the unit root test sequence was first performed before constructing model and the results were shown in the table 1 .

Table 1. Variable Stability ADF Test

\begin{tabular}{rccccc}
\hline \multirow{2}{*}{ Variable } & $\mathrm{T}$ & $\begin{array}{c}1 \% \text { critical } \\
\text { value }\end{array}$ & $\begin{array}{c}5 \% \text { critical } \\
\text { value }\end{array}$ & $\begin{array}{c}10 \% \text { critical } \\
\text { value }\end{array}$ & P value \\
\hline edr & -2.387 & -3.7500 & -3.0000 & -2.6300 & 0.1455 \\
cons & -2.726 & -3.7500 & -3.0000 & -2.6300 & 0.0696 \\
gdp & 2.881 & -3.7500 & -3.0000 & -2.6300 & 1.0000 \\
dlnedr & -5.4150 & -3.7500 & -3.0000 & -2.6300 & 0.0000 \\
dlncons & -5.3720 & -3.7500 & -3.0000 & -2.6300 & 0.0000 \\
dlngdp & -3.4890 & -3.7500 & -3.0000 & -2.6300 & 0.0083 \\
\hline
\end{tabular}

It could be seen from the table 1 that the variables $e d r$, cons and $g d p$ were non-stationary sequences at the significance level of 5\%. After taking the logarithm and difference, dlnedr, dlncons and $d \operatorname{lng} d p$ were all stable time series.

\subsection{Lag Selection}

Based on AIC, SBIC and HQIC statistics, the lag order was determined according to the information criterion minimization principle. From the table2, it could be seen AIC and HQIC statistics were minimum value when the lag order was 4 in the VAR model, but SBIC statistic was minimum if there was no lag order. Because SBIC was more likely to choose a simplified model and SBIC and HQIC would provide a consistent and actual estimate in general, the VAR model was constructed with the lag 4 in this paper.

Table 2. Lag Order Test of the VAR Model

\begin{tabular}{cccc}
\hline Lag Order & AIC & HQIC & SBIC \\
\hline 0 & -4.62947 & -4.60901 & $-4.48108^{*}$ \\
1 & -3.91567 & -3.83383 & -3.32209 \\
2 & -3.68687 & -3.54364 & -2.6481 \\
3 & -4.91733 & -4.71272 & -3.43338 \\
4 & $-5.52471^{*}$ & $-5.25871^{*}$ & -3.59557 \\
\hline
\end{tabular}




\subsection{Robustness Analysis and Granger Causality Test}

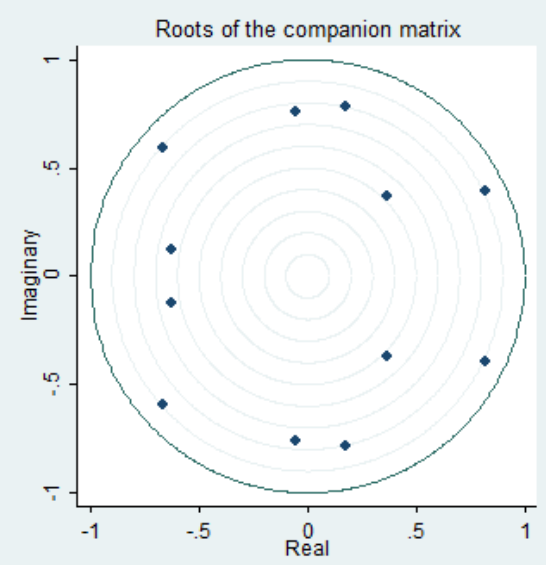

Figure 1. Unit Root Distribution of the VAR model Robustness Test

As can be seen from figure 1, all eigenvalues of the adjoint matrix were within the unit circle, so the VAR system constructed in this paper was stable.

Table 3. Granger Causality Test Results

\begin{tabular}{|c|c|c|c|c|}
\hline Equation & Excluded & chi2 & $\mathrm{df}$ & Prob>chi2 \\
\hline dlnedr & dlncons & 16.663 & 4 & 0.002 \\
\hline$d \operatorname{lne} d r$ & $d \operatorname{lng} d p$ & 8.2217 & 4 & 0.084 \\
\hline dlnedr & $A L L$ & 19. 229 & 8 & 0.014 \\
\hline dlncons & dlnedr & 12.678 & 4 & 0.013 \\
\hline dlncons & $d \operatorname{lng} d p$ & 10.608 & 4 & 0.031 \\
\hline dlncons & $A L L$ & 16. 322 & 8 & 0.038 \\
\hline$d \operatorname{lng} d p$ & $d \ln e d r$ & 64.075 & 4 & 0.000 \\
\hline$d \operatorname{lng} d p$ & dlncons & 32.413 & 4 & 0.000 \\
\hline$d \operatorname{lng} d p$ & $A L L$ & 76.25 & 8 & 0.000 \\
\hline
\end{tabular}

The Granger Causality test results were shown in table 3 and it could be seen that there were closely correlations between the elderly dependency ratio, the consumption rate and economic growth and which interacted each other as cause and effect . In the first part of the table, if $d l n e d r$ was the explained variable in the equation, the variance statistics of the dlncons and dlngdp were respectively 16.663 and 8.2217 and the corresponding p values were 0.002 and 0.084 , which could be considered that the dlncons and dlngdp were all the granger causes of the dlnedr. In second part, the $d l n e d r$ and $d l n g d p$ were also the granger causes of dlncons from the coefficient significance when the dlncons was the explained variables. And the P-values of $d$ lnedr and dincons coefficient were zero when the dlngdp was the explanatory variable in the third part, which significantly rejected the original hypothesis that both were not the granger causes of $d$ lngdp.

\subsection{Impulse-response Function and Variance Decomposition}

The impulse-response function was usually used to analysis the influence of random disturbance on the endogenous variable and the variance decomposition was used to analysis the structure impact degree on the on endogenous variable volatility to amend the parameters' actual economic meaning in the VAR model. So the impulse-response function and the variance decomposition were applied in the study and the results were shown in figure 2 and table 4. 


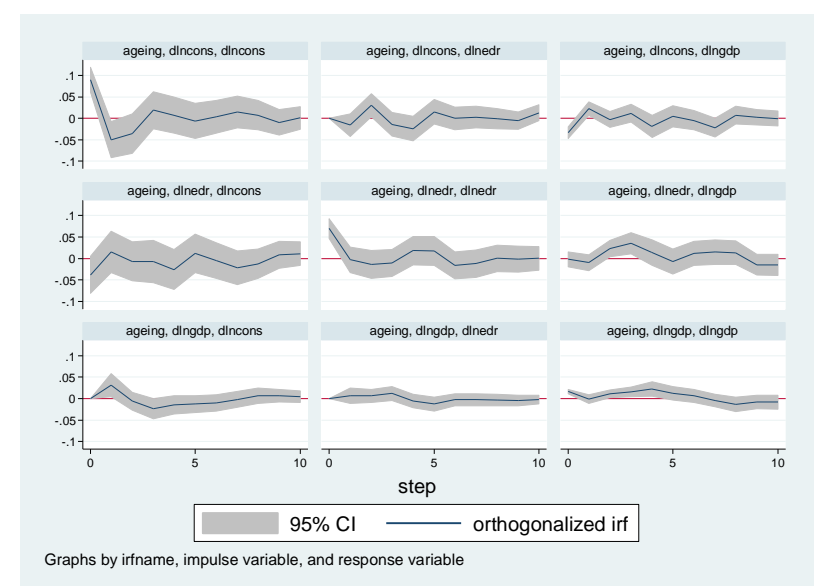

Figure 2. Normalized Pulse Response of the VAR Model

It could be seen from the figure 2 that the ratio of consumption are greatly influenced by its own within the 95\% confidence interval, and the elderly dependency ratio and economic growth would have impacts on residents consumption rate with weakening trend. But the directions were inconsistent, the influence of the aging population had a negative effect on consumption from the initial and had a positive pushing effect in the long term after the shock wave. While the economic growth had a gradually weakening positive influence on consumption fluctuation, namely that the consumption had long-term positively decreasing effects on the elderly dependency ratio and the effects were on the contrary from the economic growth. Meanwhile, the economic growth would influence by its own and the positive pulling effect on economic growth from consumption was volatile and reduced gradually, but the impact from elderly dependency ratio was gradually smooth below zero, namely its negative influence to be stable.

Table 4. Variance of Variables

\begin{tabular}{|c|c|c|c|c|}
\hline \multirow{2}{*}{$\begin{array}{l}\text { Response } \\
\text { Variables }\end{array}$} & \multirow{2}{*}{ Forecast Period } & \multicolumn{3}{|c|}{ Impulse Variables } \\
\hline & & dlnedr & dlncons & dlngdp \\
\hline \multirow{3}{*}{ dlnedr } & 1 & 1.0000 & 0.0000 & 0.0000 \\
\hline & 5 & 0.7127 & 0.2532 & 0.0341 \\
\hline & 10 & 0.6984 & 0.2487 & 0.0297 \\
\hline \multirow{3}{*}{ dlncons } & 1 & 0.1567 & 0.8433 & 0.0000 \\
\hline & 5 & 0.1506 & 0.7410 & 0.1084 \\
\hline & 10 & 0.1859 & 0.6958 & 0.1183 \\
\hline \multirow{3}{*}{ dlngdp } & 1 & 0.0022 & 0.8078 & 0.1900 \\
\hline & 5 & 0.3867 & 0.3977 & 0.2157 \\
\hline & 10 & 0.3972 & 0.3781 & 0.2248 \\
\hline
\end{tabular}

It could be seen from table 4 that the variance of the prediction of the old age dependency ratio was derived from its own, percent 69.84 from itself and percent 24.87 from the residents' consumption rate and only percent 2.97 from economic growth even if the forecast was put tenth periods forward. The influence mainly came from the ratio of consumption by self, from which there was still percent 69.58 and little affected from elderly dependency ratio but larger from economic growth if the forward 10 period. Only percent 0.2 projected variance came from the elderly dependency ratio when one forward projection for economic growth would be given and the percent would be increased along with the prolonged forecast period and would reach percent 39.72 at tenth periods. While the effects from consumption would increase to percent 22.48 at tenth period from percent 19.0 at one period and the range was relatively small. At the same time, the effects on the variance from its own would drop by percent 42.97 from one to tenth periods. 


\section{Conclusions and Suggestions}

\subsection{Conclusion and Discussion}

The vector autoregressive model was built and the relationships between the elderly dependency ratio, the ratio of consumption and economic growth taking Beijing as the empirical example. The results showed that there were close relationships between the three variable. On the one hand, there was a positive effect on the residents' consumption from the ageing population and the effect would be increase with the latter, which might related the elder demand for medical care, old-age care and other services. But the ageing would put a weakening negative effect on the economic growth, which possibly reflected that the role of the "demographic dividend" for the economy would be reduced along with the older people increase. On the other hand, with the economic and social development, the people's income level has been increasing, the social medical level has been greatly improved, and the food supply has become increasingly rich and health demands changed obviously, the elderly life quality was significantly improved. So the elders' health status has improved greatly and the population continues to increase, which further increases the speed of the aging of the population. In addition, the residents' consumption level has a positive effect on economic growth in certain period, but which would also decrease and tends to stabilize or decrease along with time past.

Due to the availability of data, the time series data used in this study was only 22 years and the data volume was relatively small, which might have a certain effect on the analysis result. At the same time, as a unique super city, there would be some difference about ageing population between the urban and rural areas and the different administrative areas in Beijing, which should be further studied and would be one important direction in our research further.

\subsection{Policy Recommendations}

From the developing history of the population structure and its trend, the elderly population in Beijing would continue to grow with the continuous development of economic society, "four old and one small” people pattern in one family would be the important family structure in future, which would result in further deepen population aging trend and have a profound impact on the residents' life and the social and economic development. Therefore, some measures should be made to realize the sustainable development in population, economic and social coordination.

Firstly, the social security system should be further perfect and the retired income level should be proper increase to enhance their expected income. The higher social awareness should be given a whole solution especially such as expensive health care, housing problem and School difficult and so on to enhance the families' palm ability on the consumption and to improve the elderly consumption willingness and consumption level, which would make them have the ability to consumption, dear to consumption and willing to consumption.

Secondly, the endowment industry cluster should be actively cultivated oriented by market mechanism and the government-led, social participation, multiple input pattern should be encouraged. The social endowment service system, which is on the basis of the home and depended on community and supported by other companies, should be speeded up the formation to promote the services industry scale, industrialization and continuously improve the quality of the elders' life.

Thirdly, functional health food for the elders should be further intensified especially aim to the noncommunicable diseases old peoples such as the cardiovascular, high cholesterol and high blood pressure persons. The Chinese Old People Dietary Guidelines should be further promoted and make their food consumption structure optimized and upgraded to better the health conditions and to improve their spending willingness and the level of consumption.

\section{Acknowledgments}

The study was funded by the Beijing natural science foundation (9173025) and the Innovation Project of Chinese Academy of Agricultural Sciences (CAAS-ASTIP-2016-AII). 


\section{References}

[1] Li Jianmin. Consumption Demand of the Chinese Elderly: An Analysis of the Affecting Variables with Projection[J].Population \& Economics,2001,5:10-16.

[2] Clark R. L. and Spengler J. J. The Economics of Individual and Population Aging[M].Cambridge University Press,1980.

[3] Modigliani F, Cao S L. The Chinese Saving Puzzle and the Life-cycle Hypothesis[J].Journal of Economic Literature,2004,1:145-170.

[4] Horioka C.Y. and Wan J. The Determinants of Household Saving in China: A Dynamic Panel Analysis of Provincial Data. NBER Working Paper,2006.

[5] Wang Xia. An Empirical Study on the Relationship between Population Age Structure and Household Consumption[J].Theoretical Economic Research,2015,4:25-30.

[6] Zhang Donggang. An Analysis of the Factors of Regulating Alteration of Consumer Demand: The Case of Modern JaPan [J].Nankai Journal,2003,5:64-70.

[7] Li Xiang, Wang Kai, Lv Meiye. Population Age Structure and Rural Residents' Consumption: Theoretical Mechanism and Empirical Test [J].Jianghai Academic Journal,2010,2:93-98,239.

[8] Li Chunqi, Zhang Jieping. The Effect of the Transformation of Chinese Population Structure on the Consumption of the Rural Residents[J].Chinese Journal of Population Science,2009,4:14-22.

[9] Wang Yupeng. The Impact of Population Aging on Urban Household's Consumption Behavior in China[J]. Chinese Journal of Population Science,2011,1:64-73,112.

[10] Shan Yi. Prospects for the Changes of Residents' Consumption Structure in China Under the Background of Aging [J].Journal of Commercial Economics,2015,23:46-48.

[11] Wang Jia-xu. Research on the Influence of Population Aging on the Consumption Disparity of Chinese Rural and Urban Residents_-Based on the Empirical Analysis of Provincial Dynamic Panel Data[J].Modern Economic Science,2015,37(5):109-115.

[12] Wang Sen. Empirical Analysis on the Relation between Population Aging and Resident Consumption in China:Based on the Data from 1978 to 2007 [J].Northwest Population Journal,2010,1:22-27.

[13] Cai Fang. Demographic Transition, Population Dividend, and Sustainability of Economic Growth: Minimum Employment As A Source of Economic Growth[J].Population Research,2004,28(2):2-9.

[14] Peng Xiujian. Macroeconomic Consequences of Population Ageing in China: A Computable General Equilibrium Analysis[J]. Population Research,2006,30(4):12-22.

[15] You Shibing, Cai Yuanfei. Dynamic Analysis of the Population Aging Effects on Economy Growth[J].Economy and Management,2017,31(1):22-29.

[16] Ling Ling. Association Analysis of Population Aging, Household Consumption and Economic Growth_-A VAR Model-based Empirical Analysis[J].Journal of Hebei GEO University,2013,36(2):5-9.

[17] He Ju-huang. The Effect of Population Change on Economy[J].Population \& Economics,2004,2:1-6.

[18] Li Jun. The Balanced Economic Growth Path under the Aging Population[J].The Journal of Quantitative \& Technical Economics,2006,8:11-21.

[19] Liu Yongping, Lu Ming. Analysis on Whether the Aging Chinese Economy Can Continue to Increase from the Perspective of Family Pension[J]. The Journal of World Economy,2008,1:65-77.

[20] Liu Luning. Empirical Study on the Effect of the Aging of the Population on the Consumption 
Structure of Beijing[J]. Journal of Beijing Vocational College of Labour and Social Security,2015,89(9):3-7.

[21] Gao Ying, Zhang Xiulan. Analysis on the Characteristics and Changing Trends of Population Structure in Megalopolis:The Case of Beijing [J].Population Journal,2016,2:18-28. 